\title{
CARREIRA, D.; PINTO, J. M. R. Custo aluno- qualidade inicial: rumo à educação pública de qualidade no Brasil. São Paulo: Global: Campanha Nacional pelo direito à Educação, 2007.
}

\author{
Por Gabriela Schneider
}

No Brasil, ainda hoje, a lógica que permeia o financiamento da educação e, portanto o gasto por aluno é baseada na divisão entre os recursos da vinculação orçamentária e o número de alunos matriculados. Tal medida não tem sido capaz de garantir um padrão mínimo de qualidade, padrão este amplamente referido em diversos documentos legais.

Nesse sentido o livro Custo aluno-qualidade inicial se insere dentro de uma nova forma de pensar o financiamento da educação ao trazer como principal objetivo definir um padrão mínimo de custo por aluno capaz de ampliar o acesso das pessoas na escola, responder as necessidades dos alunos e atender o que está disposto no Plano Nacional de Educação (2001). O ideal de um Custo aluno-qualidade (CAQ) é a principal bandeira da Campanha Nacional pelo direito à Educação que se insere como movimento que luta por uma educação de qualidade para todos.

Para definir esse custo aluno, os autores dividem o livro em cinco partes, na busca por construir uma trajetória capaz de colaborar na elaboração da matriz do $C A Q$, tendo ciência que esta definição é inicial e, portanto deve ser apenas o primeiro passo na caminhada da melhoria da qualidade educacional brasileira.

Para iniciar esse caminho Carreiro e Pinto (2007) apresentam um histórico da questão da qualidade ou da falta dessa nas políticas educacionais, uma vez que entendem que a qualidade é um conceito histórico e socialmente construído que está em constante disputa e que em cada momento histórico representa um ideal, um conceito diferenciado, daí a necessidade de se explicitar o que se entende por qualidade.

Sendo assim, os autores apresentam alguns aspectos que permearam a história da discussão das políticas educacionais, mostrando que a questão da falta de qualidade na escola pública é antiga e que quando ela avança em termos qualitativos se torna elitista, por outro lado, no momento que se amplia o acesso diminuemse os gastos. Tópicos como quantidade versus qualidade, acesso versus permanência também permearam a discussão da qualidade educacional no Brasil. Além é claro de discursos neoliberais que entendem a qualidade como eficiência, em que se buscava usar a lógica da produção fabril para a escola, idéia que foi bastante criticada especialmente na década de 1990, quando se percebeu que a qualidade poderia sim deixar de ser um debate neoliberal e representar a garantia dos direitos de todos.

Em relação à qualidade, afirmam Carreira e Pinto: "Então no campo educacional, temos hoje uma disputa sobre as diversas maneiras de se alcançar a qualidade. São perspectivas distintas, nas quais a qualidade se configura em várias pautas, projetos políticos, ideológicos e utopias" (2007, p. 21)

Nesse sentido, busca-se pensar a qualidade dentro de uma perspectiva democrática, tomase a equidade em uma dimensão ampla e 
reflete-se sobre que tipo de qualidade se quer e o que ela promove. No livro os autores definem o conceito como um processo em que se tem uma formação para toda e qualquer pessoa, respeitando suas peculiaridades e diferenças de forma democrática, justa e pensando no ser humano completo e complexo.

Ainda nesse capítulo Carreira e Pinto (2007, p. 26) demonstram as bases em que se assenta a matriz do $C A Q$, afirmando que ela busca trabalhar com três recortes: equidade (econômica, gênero, raça/etnia, necessidades especiais, etc), insumos (condições de estrutura e funcionamento, valorização profissional, gestão democrática, acesso e permanência) e etapas e modalidade (Educação infantil, fundamental, média, de jovens e adultos, do campo, especial, indígena, à distância) dentro de três dimensões: estética, ambiental e de relacionamento humano.

No segundo capítulo apresenta-se a realidade educacional brasileira na atualidade, apresentando os desafios a serem enfrentados. Os autores mostram que apesar do avanço em termos de acesso ainda há muito que fazer e que isso se amplia muito mais no que se refere à garantia de permanência dos alunos na escola. Explicita-se a falta de formação dos professores, os baixos índices de conclusão, especialmente do ensino médio, falta de estrutura e equipamentos, o pouco tempo de permanência dos alunos na escola, as grandes desigualdades e disparidades educacionais (em termos de localização e rede pública e particular), o baixo acesso a universidade das camadas mais pobres, especialmente a pública. Para finalizar este capítulo mostra-se que o custo-aluno do Brasil é muito inferior a outros países da América do Sul, e nem se compara aos países de primeiro mundo.

O capítulo três expõe a legislação educacional brasileira, mostrando os pontos favoráveis, avanços e retrocessos que esta trouxe para a definição de custo aluno-qualidade. Inicialmente se tem a Constituição como marco de garantia de um padrão mínimo de qualidade para todos, contudo até a aprovação do FUNDEF (Fundo de Manutenção e Desenvolvimento da Educação
Fundamental e Valorização do Magistério) em 1996 não havia preocupação com padrão mínimo de qualidade. O FUNDEF estabeleceu um prazo de cinco anos para o estabelecimento de recursos mínimos para o $C A Q$, o prazo venceu em 2001 e ainda não se vê o CAQ em prática.

Mas, o FUNDEF foi substituído pelo FUNDEB (Fundo de Manutenção e Desenvolvimento da Educação Básica e Valorização do Profissionais da Educação) e amplia os impostos vinculados, bem como as modalidades de atendimento, e estabelece a participação da comunidade na definição do $C A Q$, contudo ainda deixa a desejar em termos de definição dos conceitos em relação ao fundo substituído. A Lei de Diretrizes e Bases da Educação Nacional - LDB (1996) também é um marco importante na educação, bem como para o $C A Q$, pois vai estabelecer o que serão os padrões mínimos de qualidade, além de definir como serão calculados. Além disso, apresenta-se - Plano Nacional de Educação que traz diversos elementos necessários a se considerar quando se pensa a qualidade da educação. Os autores ainda apresentam a questão da formação e remuneração dos profissionais da educação na legislação como ponto fundamental do CAQ.

O capítulo quatro vai apresentar os diversos movimentos feitos pela sociedade civil lutando por uma educação pública, gratuita e de qualidade para todos, uma luta histórica e atual, caracterizada por uma "Atuação que envolveu criatividade, suor, lágrimas, conquistas, derrotas, dúvidas, contradições, medos, risos, competência e, sobretudo, esperanças e sonhos. Muitos coletivos e pessoas anônimas e públicas lutaram e trabalharam antes, e muitas outras virão depois de nós" (CARREIRO \& PINTO, 2007, p. 67).

Essas atuações colaboraram para garantir expressivos ganhos na Constituição Federal do Brasil CF (1988), no Estatuto de Criança e do Adolescente (ECA, 1990) e na própria LDB (1996), que apesar de não ter sido aprovado a proposta construída pela sociedade civil integralmente, sua elaboração representou um momento de muita discussão e reflexão em torno da educação pública brasileira. 
Os autores ainda citam como marcos importantes de discussão e ação pela educação: Conferência Nacional de Educação para Todos (Jomtien, 1990) que acabou por formular uma Declaração com o Compromisso Nacional de Educação para Todos. O Plano Nacional da sociedade civil que buscava apresentar os anseios e desejos da sociedade civil para a educação, buscava-se nesse documento que os gastos públicos com educação atingissem 7\% do Produto Interno Bruto (PIB). Também o movimento FUNDEB pra valer que buscava batalhar perante as fragilidades da lei que instituía esse fundo.

Além é claro da Campanha Nacional pelo Direito à Educação que "surge com o desafio de somar diferentes forças políticas pela efetivação dos direitos educacionais garantidos por lei em torno de uma agenda com poucas metas e com um modo funcionamento da campanha, priorizando ações de mobilização, pressão política e comunicação" (CARREIRO \& PINTO, 2007, p. 73).

O quinto e último capítulo "Um primeiro passo rumo à qualidade que almejamos: o CAQi", como o próprio nome já expressa, vai tratar da matriz que estabelece padrões mínimos de qualidade para a educação, os autores ressaltam que esses padrões não são os desejados, mas o primeiro passo para chegar a tal, por isso chama-se custo aluno-qualidade inicial.

Para Carreira e Pinto o valor definido pelo CAQi pode ser posto em prática pelos governos se assumido como prioridade, sendo que o CAQi é um processo e não um valor fixo, e tem como objetivo estabelecer um padrão mínimo de qualidade, que deve variar conforme a modalidade educacional, assegurandoremuneração condigna a todos os profissionais e buscando combater as desigualdades e a iniqüidade.
Para tanto, considera-se fundamental definir não apenas o conceito de qualidade mais quais são os insumos capazes de garantir uma escola de qualidade, sendo necessário para tanto levar em consideração os fatores que interferem na definição do CAQi: tamanho da escola/creche; jornada dos alunos; relação alunos-turma e alunos-professores; salários dos professores.

Assim, a partir dessas definições se estabeleceu para cada etapa de ensino uma "escola típica", buscando descrever todas as quantidades e custos dos insumos necessários, dos bens e serviços bem como da administração do sistema. Essas matrizes demonstraram que o valor investido em todas as etapas da educação básica é aquém do valor definido como imperativo para garantir um CAQi, especialmente no que se refere a educação infantil. Além disso, percebeu-se que ao contrário do custo estipulado atualmente, o ensino fundamental séries iniciais custa mais que as séries finais.

Com a adoção do CAQi é possível colocar o Brasil "em uma situação mais próxima daquela ocupada pelos seus vizinhos sul-americanos e muito mais adequada aos interesses de sua população" (CARREIRO \& PINTO, 2007, p. 112).

Por fim, os autores trazem sugestões como aumentar a vinculação dos impostos, utilizar o dinheiro das estatais, a necessidade de se pensar um CAQi para outras modalidades da educação (do campo, indígena, etc) buscando sempre a melhoria da qualidade de ensino. Sem dúvida esse livro traz uma forte contribuição para pensar o financiamento educacional e as necessidades presentes no interior da escola. Sendo assim, parece uma leitura imprescindível a todos os profissionais da educação engajados com uma educação de qualidade para todos, especialmente aqueles que se dedicam ao estudo das políticas educacionais e do financiamento da educação. 